\title{
DESENVOLVIMENTO COMO RESULTADO DO CRESCIMENTO ECONÔMICO E DA DEMOCRACIA: $O$ PAPEL DOS MOVIMENTOS SOCIAIS DE JUNHO DE 2013
}

\author{
DEVELOPMENT AS A RESULT OF ECONOMIC GROWTH AND \\ DEMOCRACY: THE ROLE OF SOCIAL MOVEMENTS OF JUNE 2013
}

\author{
Marcelo Guerra Martins ${ }^{\mathrm{I}}$ (6) \\ Greice Patrícia Fuller ${ }^{\mathrm{II}}$ (1)
}

\footnotetext{
${ }^{\mathrm{I}}$ Centro Universitário das Faculdades

Metropolitanas Unidas, São Paulo,

SP, Brasil. Doutor em Direito. E-mail: marcelo.martins@fmu.br

II Centro Universitário das Faculdades
Metropolitanas Unidas, São Paulo, SP,
Brasil. Doutora em Direito. E-mail:
greice.fuller@fmu.br
}

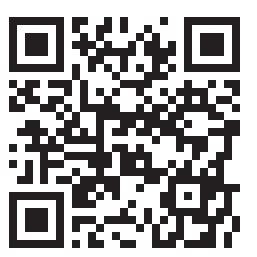

DOI: http://dx.doi.org/10.31512/rdj.v20i38.161

Recebido em: 13.05.2019

Aceito em: 05.04.2020
Resumo: $\mathrm{O}$ presente artigo trata das principais características institucionais capazes de gerar o desenvolvimento dos países, com destaque para a necessidade de haver, de modo conjunto, estímulos ao crescimento econômico, ao aprimoramento constante da educação e da qualificação do capital humano, à acumulação de conhecimento e tecnologia, à baixa tolerância das pessoas para com a corrupçáo, devendo a dinâmica social ocorrer sob um ambiente democrático, com livre manifestação de pensamento e crítica. O texto também analisa os movimentos sociais ocorridos em junho de 2013 no Brasil, tidos como um fenômeno possibilitado pela conjuntura própria da atual Sociedade da Informação. Conclui-se que "junho de 2013" inaugurou uma nova maneira de se exercer a cidadania e representou um avanço institucional em direção à aversão generalizada à corrupção de governos e autoridades públicas. Em termos de metodologia, o texto se constitui num estudo teórico (revisão bibliográfica), com abordagem de índole qualitativa e conclusóes obtidas pelo método indutivo.

Palavras-chave: Democracia. Instituiçóes. Cidadania. Movimentos Sociais de Junho de 2013.

Abstract: This paper deals with the main institutional characteristics capable of generating the development of the countries, wth emphasis on the need to jointly stimulate economic growth, the constant improvement of education and the qualification of human capital, the accumulation of knowledge and technology, low tolerance of people towards corruption, and social dynamics should occur under a democratic environment, with free expression of thought and criticism. The text also analyzes the social movements that took place in June 2013 in Brazil, considered as a phenomenon made possible by the current situation of the Information Society. It is concluded that "June 2013" inaugurated a new way of exercising citizenship and represented an institutional advance toward general aversion to corruption of governments and public authorities. In terms of methodology, the text is a theoretical study (bibliographic 
review), with a qualitative approach and conclusions obtained by the inductive method.

Keywords: Democracy. Institutions. Citizenship. Social Movements of June 2013.

\section{Introdução}

O presente artigo trata das instituiçóes como os principais indutores do desenvolvimento dos diversos países, ou seja, um estágio econômico e social em que a maioria da população apresenta condições de vida dignas. No caso, as instituiçóes correspondem não somente às normas jurídicas, mas também englobam a maneira de sua aplicação, bem como as convençôes, valores e crenças de uma sociedade fixados a partir da influência de fatores históricos, culturais e religiosos.

O texto está dividido em cinco seçôes, sendo a primeira dedicada à introdução. $\mathrm{Na}$ segunda, são abordas as características institucionais que estimulam o desenvolvimento, a começar pelo crescimento da economia e da renda per capita. Desta feita, são elencados aspectos como respeito à propriedade e aos contratos; segurança jurídica e previsibilidade do comportamento judicial; aplicação impessoal e isonômica das leis; sistema de mercado predominantemente livre; educação, estímulo à qualificação da mão de obra e acumulação de conhecimento; baixa tolerância dos indivíduos com a corrupção e a necessidade da dinâmica social se operar dentro de um ambiente democrático, sob a mais ampla liberdade política e de manifestação do pensamento, seja pela imprensa tradicional ou mesmo através das redes sociais eletrônicas.

Nas seções três e quatro são descritos e analisados os movimentos ocorridos no Brasil em junho de 2013, ocasiáo em que milhóes de pessoas foram às ruas, em diversas cidades por todo o território nacional, para protestar contra a corrupção. O ineditismo dos aludidos movimentos permite considerá-los como um marco histórico que inaugurou uma nova maneira de exercer a cidadania e, por conseguinte, encarar a própria democracia. Dentre outras circunstâncias, não houve prévia convocação por parte de partidos políticos, sindicatos ou associaçóes de classe. Os movimentos surgiram espontaneamente, organizados de forma difusa principalmente através das redes sociais. A quinta e última seção corresponde às conclusōes.

Nessa banda, é destacado o contexto da atual Sociedade da Informação, que tem como uma de suas marcas a circulaçáo de ideias, informaçóes e conhecimento por meio de redes como a internet, sempre de maneira cada vez mais rápida e abrangente. Essa conjuntura informacional funcionou como pedra angular que náo apenas possibilitou a eclosão dos movimentos de junho de 2013, mas, sobretudo, moldou o caráter dessas manifestaçôes. 
Acreditamos que a relevância do tema deriva da sua atualidade e relativo ineditismo, sendo perceptível que esse tipo de manifestação popular pública, precedida de conclamação oriunda das redes sociais, é um fenômeno que tende a crescer e a se consolidar como importante braço da cidadania que, desse modo, cada vez mais deixa de ser vista sob o aspecto meramente formal do direito de votar por ocasião das eleiçóes.

Em termos de metodologia, o presente texto se apresenta como um estudo teórico (revisão bibliográfica), com abordagem de índole qualitativa, sendo as conclusões obtidas essencialmente pelo método indutivo.

\section{Instituiçóes como elementos chave para o desenvolvimento}

Uma das acepções possíveis para o termo "desenvolvimento" é a presença de qualidade de vida digna para a maioria das pessoas que compóem uma nação. Tratase, outrossim, de "um processo contínuo pelo qual a disponibilidade de bens e serviços cresce em proporção superior ao do incremento demográfico de uma dada sociedade" (NUSDEO, 2005, p. 354). Nesses termos, o desenvolvimento é algo bastante recente em termos históricos, sendo certo que, até uns 200 ou 300 anos atrás, a pobreza generalizada era o que prevalecia, salvo "uma minoria muito pequena de governantes e grandes proprietários de terras. A vida era táo difícil em boa parte da Europa quanto na Índia ou na China” (SACHS, 2005, p. 53).

Porém, a partir do final do século XIX e durante todo o século XX, a economia mundial passou a experimentar um crescimento vertiginoso. Nessa linha, "em menos de dois séculos, de 1820 a 1998, o crescimento explodiu: 1800\%! (NÓBREGA, 2005, p. 58. Todavia, em que pese o crescimento econômico ter se acentuado nos últimos séculos, é sabido que o fenômeno não ocorreu de modo uniforme em termos globais. Enquanto algumas regióes (v.g. América do Norte, Europa Ocidental, Japão, Austrália, Nova Zelândia) majoraram significativamente suas rendas per capita, outras (v.g. América Latina, África e Ásia) não obtiveram o mesmo êxito. Com efeito, variaçôes significativas no ritmo de crescimento econômico dos países vêm ocorrendo e se intensificando nos últimos dois séculos.

Nesse tópico, Cooter e Ulen (2010, p. 71) aduzem que no início do século XX "a renda per capita da Argentina era semelhante à do Canadá, e hoje a do Canadá é mais de três vezes mais alta. Depois da $2^{\text {a }}$ Guerra Mundial, a Coréia e a Nigéria tinham uma renda per capita semelhante, e hoje a da Coréia é 19 vezes mais alta”. Os autores também noticiam que a renda per capita da África subsaariana regrediu 25\% desde 1975 (idem, p. 71).

A busca para explicar essas discrepâncias já trouxe diversas teorias. Uma delas, talvez a mais absurda, aduz que nos locais de altas temperaturas (regióes dos trópicos) 
as pessoas seriam mais letárgicas e menos interessadas em trabalhar para gerar riquezas, o que condenaria à estagnação econômica os países localizados nessas regióes. Noutra banda, já se ouviu dizer que os países colonizados pela Inglaterra, cujos sistemas jurídicos inspirados pela common law seriam mais pragmáticos e preocupados com a eficiência econômica, teriam se saído melhor do que os países que tiveram colonização ibérica, de índole mais burocrática e exploratória.

Outros atribuem a culpa pela pobreza de muitos povos na suposta exploração engendrada por naçóes ricas e desenvolvidas, que, dentre ou males, teriam espalhado empresas multinacionais para aproveitarem-se da mão de obra barata presente em países mais pobres. Porém, nenhuma dessas "explicações" é realmente satisfatória.

Por primeiro, temperaturas altas e o clima náo são elementos determinantes do destino econômico de um país. A Austrália, por exemplo, cujo calor no verão se aproxima dos $50^{\circ}$ Celsius, é reconhecida como um país bastante desenvolvido. Igualmente, diferenças econômicas e sociais significativas são encontradas em regiôes bastante próximas. É o caso do sul da Espanha que ostenta um estágio de desenvolvimento bem superior ao Marrocos, não obstante apenas algumas dezenas de quilômetros separarem esses países. O que não dizer, então, das duas Coreias, localizadas na mesma península, mas com índices de qualidade de vida e liberdade bastante diversos.

Prosseguindo, o fato de um país ter experimentado a colonização britânica pouco teve a ver com o seu progresso futuro. Mesmo que Estados Unidos, Canadá, Austrália e Nova Zelândia tenham sido exitosos em conferir condiçóes dignas à maioria de seus habitantes, o mesmo não se deu com diversas outras colônias inglesas, tais como África do Sul, Índia, Egito, Nigéria, Serra Leoa, Gâmbia, Uganda, Zimbábue, etc.

E, explicar a pobreza de muitos países numa suposta exploração perpetrada por naçóes ricas apenas seria aceitável caso o produto mundial bruto tivesse permanecido estável, com uma parcela considerável sendo remetida para as regióes mais prósperas. Contudo, ao que parece, não foi isso que ocorreu. Com efeito:

O produto mundial bruto aumentou quase cinqüenta vezes. Todas as regióes do mundo experimentaram algum crescimento econômico (tanto em termos de tamanho total da economia como quando medido por pessoa), mas algumas regióes tiveram um crescimento muito maior que outras (SACHS, 2005, p. 58).

Ocorre que os países ricos produziram bens e serviços em muito maior quantidade e valor agregado do que os demais, sendo a criação de empresas multinacionais um reflexo desse fenômeno e não a sua causa. Ademais, se as multinacionais fossem tão prejudiciais ao desenvolvimento, certamente os países ricos não deixariam que esse tipo de empresa se instalasse em seus territórios, o que, como sabido, não acontece, sendo certo que diversas companhias desse quilate se encontram espalhadas por praticamente todos os países da Terra, ricos ou pobres. 
Então, qual seria a melhor explicação para o fato de alguns países terem prosperado e outros não? A resposta mais aceita atualmente indica que, na realidade, as instituiçóes forjadas lentamente ao longo do tempo são os elementos mais relevantes para deflagrar um círculo virtuoso de desenvolvimento ou, ao contrário, gerar estagnação ${ }^{1}$. No caso, segundo North (1994, p. 360), instituições devem ser consideradas como:

obstáculos criados pelos seres humanos para estruturarem a interação social. Elas são constituídas por restriçóes formais ( $v$.g. regras, leis, constituiçóes), informais ( $v$ g. normas de comportamento, convençóes, códigos de conduta auto impostos) e os modos como são aplicadas. Juntas definem os estímulos à formação da estrutura social, especialmente das atividades econômicas².

Resumindo, as instituições correspondem não apenas às normas jurídicas, mas englobam também o modo, a extensão e a efetividade de sua aplicação, bem como as convençóes e crenças existentes no bojo de uma sociedade (v.g. o papel da família, da religião, das forças armadas, a tolerância com a divergência, etc.). Considerando que cada povo apresenta elementos históricos e culturais próprios, com algumas semelhanças aqui e acolá, é mais do que esperado encontrar diversidade no conteúdo institucional de cada país. Desse modo, surge uma questão de fundamental importância: quais as características primordiais devem apresentar as instituições de um país para gerarem o seu desenvolvimento? É o que passamos a discorrer.

Primeiramente, é indispensável que as instituições induzam ao crescimento econômico. Ainda que uma elevada renda per capita não resulte de forma automática no surgimento de condições de vida digna para parcela ampla da população, o fato é que essa condição não pode ser alcança sem que a economia seja, efetivamente, robusta e, desse modo, existam recursos excedentes a serem redistribuídos aos mais necessitados por meios de políticas públicas variadas. Com efeito, é certo que "maiores índices de educação e de longevidade dependem do crescimento econômico" (SOUZA, 2008, p. 18).

Ademais, é fato que o crescimento econômico constante pode reduzir a pobreza de maneira relativamente apartada das políticas distributivas (BARROS e MENDONÇA, 1997 , p. 06). Segundo os autores, tomando como base a situação brasileira de 1993, um crescimento econômico da ordem de $3 \%$ ao ano, durante uma década, seria capaz

$1 \mathrm{O}$ papel das instituições como instrumentos chave para o desenvolvimento dos países é defendido, dentre outros, por: GALA (2003, p. 90); ZYLBERSZTAJN e SZTAJN (2005, p. 03); ACEMOGLU e ROBINSON (2012, p. 06 e seg.). Segundo North (1991, p. 26-27), "In the case of Netherlands and England, decentralized control produced an adaptively efficient set of institutions that adjusted to changing needs; thus, competition gradually forced the development of more efficient institutions and instruments the promoted commerce and trade, and, in consequence, lowered transaction costs in these economies. The bureaucracies of Spain, Portugal, and France, on the other hand, lagged behind, stifling initiatives that would have induced increased productivity, and Spain and Portugal pursued a downward path that would continue for centuries".

$2 \mathrm{O}$ texto original é o seguinte: "Institutions are the humanly devised constraints that structure human interaction. They are made up of formal constraints (e.g., rules, laws, constitutions), informal constraints (e.g., norms of behavior, conventions, self-imposed codes of conduct), and their enforcement characteristics. Together they define the incentive structure of societies and specifically economies". 
de reduzir em oito pontos percentuais a pobreza (de 35\% para 27\%). Um crescimento menor, na casa dos $2 \%$ ao ano, reduziria a pobreza em cinco pontos percentuais ao final de uma década e, por fim, um crescimento econômico de 5\% ao ano, sempre considerando o período decenal, poderia diminuir a pobreza em treze pontos percentuais.

E, em termos de instituições e de estrutura do sistema jurídico ${ }^{3}$, o estímulo ao crescimento econômico será tanto maior quanto mais presentes estiverem os seguintes elementos: 1) respeito à propriedade e aos contratos; 2) segurança jurídica e previsibilidade do comportamento judicial; 3) aplicação impessoal e isonômica da lei, sem privilégios ou particularidades específicas, inclusive de índole tributária ${ }^{4}$ e, por fim, 4) sistema de mercado predominantemente livre.

A não proteção legal adequada e suficiente aos direitos de propriedade, além de impedir a exploração racional dos recursos disponíveis, induz à economia de subsistência e usualmente gera um clima de violência onde a "lei do mais forte" acaba prevalecendo, com provável grande número de pessoas feridas ou mesmo mortas. No artigo The tragedy of the commons, Garret Hardin pondera que quando os recursos disponíveis são compartilhados (sejam recursos naturais ou a força de trabalho) há uma tendência de exploração abusiva e não racional pelos indivíduos.

No caso, o autor faz alusão à propriedade comunal típica da Idade Média em que cada vila possuía uma área comum onde era possível às pessoas deixarem seus animais pastarem livremente, sem uma limitação clara acerca desse direito. Dessa forma, cada aldeão tinha um incentivo de colocar para pastar o máximo de animais possível na área comum. Porém, como todos tinham o mesmo incentivo, o campo era utilizado de forma não racional, acima de sua capacidade de regeneração até o exaurimento, com prejuízo para todos (HARDIN, 1968, p. 1.244). Noutro giro, se cada aldeão fosse proprietário de uma área definida, de forma que somente nela poderia deixar seus animais pastando, provavelmente a exploração seria mais racional e não chagaria a exaurir a terra 5 .

$3 \mathrm{O}$ sistema jurídico vem sendo "crescentemente percebido como elemento relevante para o processo de desenvolvimento” (BARRAL, 2005, p. 48).

4 Segundo alguns estudos, de forma geral, um sistema tributário para ser considerado de "boa qualidade" deve conter conjuntamente as seguintes características: 1) capacidade de arrecadação satisfatória; 2) isonomia (não ocorrência de regimes tributários especiais ou privilegiados para setores específicos da economia beneficiados com isençóes, alíquotas zero, créditos presumidos, barreiras alfandegárias, etc.); 3) equidade (sacrifício fiscal proporcional e equivalente entre ricos e pobres); 4) simplicidade (não ocorrência de excesso de burocracia ou complexidade para o cumprimento das obrigaçóes tributárias) e 5) neutralidade (o ônus tributário não deve distorcer os preços na economia) e 6) transparência (periódica prestação de contas pelos governos acerca da aplicação dos recursos arrecadados). Sob tais quesitos, o sistema tributário brasileiro é de "péssima qualidade" (vide LIMA, 1999, p. 0609; APPY et. al., 2016). Todavia, opta-se por não aprofundar esse tópico para que não haja desvio em relação ao tema central proposto.

5 Algo semelhante pode ocorrer, por exemplo, nos gastos em um restaurante. Se a conta for dividida "por pessoa", independentemente do consumo de cada um, há uma tendência para se gastar mais, uma vez que, via de regra, as pessoas não gostam de patrocinar eventuais abusos ou luxos alheiros, na linha do "se é para gastar, então que eu aproveite também”. O problema é que se todos pensarem da mesma forma, e isso é o que 
A mesma proteção legal deve ser conferida à força obrigatória dos contratos que, em suma, visam "assegurar e regular a pacífica circulação de riqueza; evitar a violência na alocação eficiente dos bens na economia; e a promover sua transferência entre as pessoas de forma lícita, uma vez que obriga as pessoas por suas declaraçóes e promessas" (SZTAJN e VERSOÇA, 2003, p. 09). É bem sabido, segundo assevera Serpa Lopes (1996, p. 35), que o contrato atualmente "representa o centro da vida dos negócios, o instrumento prático, que atua sob as mais variadas finalidades da vida econômica, os quais implicam a composição dos interesses inicialmente opostos, ou, quando menos, não coincidentes”.

Ademais, ao contratar as partes criam expectativas umas em relação às outras, inclusive no que tange à assunção dos riscos incorridos no negócio. Daí ser legítimo presumir que, uma vez celebrado o pacto, as partes passam a ocupar posição melhor do que aquela anterior. Caso contrário, não teriam contratado. Daí a máxima romana do pacta sunt servanda, devendo ser a revisão contratual decretada judicialmente evento excepcional e restrita a hipóteses legalmente bem delineadas. Nessa toada:

É fácil perceber que as transações serão maximizadas se inseridas num ambiente institucional favorável que tenda a minimizar perdas. Portanto, fatores tais como segurança jurídica (quanto à imutabilidade do pacto), previsibilidade (elemento ligado aos riscos do negócio) e exeqüibilidade (execução forçada em caso de inadimplemento), devem ser considerados - e fortemente albergados - pelo sistema normativo, sob pena de gerar desestímulo aos agentes econômicos, pelo aumento dos custos de transação (MARTINS, 2016, p. 100-101).

Dessa forma, o respeito à propriedade e aos contratos são essenciais a qualquer tipo de investimento. Com isso entra em cena a segurança jurídica, outro elemento indispensável ao crescimento econômico ${ }^{6}$. Na verdade, segurança jurídica é um conceito amplo e que envolve, além do respeito à propriedade e aos contratos, vários outros aspectos atinentes ao ordenamento jurídico, destacando-se, dentre outras características, a clareza, a estabilidade e a irretroatividade normativa como um todo, de maneira a que os efeitos oriundos das relaçóes estabelecidas e aperfeiçoadas no passado não possam ser modificados no futuro, mesmo que por lei. Nesse tópico, é indispensável que o ordenamento jurídico respeite o direito adquirido, o ato jurídico perfeito e a coisa julgada, como inclusive prevê a atual Constituição brasileira (art. 5º, XXXVI).

Mas não é só. Dentro do elemento segurança jurídica inclui-se também a presença de uma certa (ou razoável) previsibilidade do comportamento judicial na resoluçáo dos casos concretos. Com efeito, decidir de modo uniforme proporciona: estabilidade, irretroatividade e uniformidade (COSTA, 2011, p. 109-110). Para tanto, é muito importante que os precedentes jurisprudenciais das Cortes mais elevadas do sistema sejam

normalmente ocorre, a conta final fica bem mais elevada do que se cada um pagasse apenas pelo que tivesse consumido.

6 Com efeito, "a evidência empírica sugere que países com menor grau de segurança jurídica se afastam das melhores práticas de produção e, assim, crescem mais devagar” (PINHEIRO, 2009, p. 39). 
referendados pelas instâncias inferiores ${ }^{7}$. A previsibilidade do comportamento judicial é uma varável usualmente analisada pelos agentes econômicos, sendo certo que:

os mercados funcionam de forma mais eficiente se ligados a um ambiente institucional estável, no qual os agentes econômicos podem calcular, i. e., razoavelmente prever o resultado de seu comportamento e o daqueles com quem se relacionam (FORGIONI, 2006, p. 37).

Uma jurisprudência dividida e oscilante contribui para gerar incerteza que, por sua vez, é incorporada como elemento que majora o risco da atuação econômica. $\mathrm{O}$ problema é que, aumentando-se "o risco, reduz-se o diferencial entre a taxa de retorno dos investimentos e a taxa de retorno considerada mínima, inviabilizando a acumulação de capital" (SOUZA, 2008, p. 299). Dessa forma, investimentos que poderiam gerar empregos e outras benesses sociais simplesmente não saem do papel.

Ademais, um ambiente em que haja previsibilidade do comportamento judicial se coaduna com a isonomia, outro valor de inegável relevo nas sociedades ocidentais, inclusive a brasileira, na forma de tratamento judicial paritário a situaçóes juridicamente equivalentes, o que póe em destaque o terceiro elemento acima indicado como indutor do crescimento econômico, qual seja, a aplicação impessoal e isonômica da lei. Como justificar que situações regidas por uma mesma legislação possam obter resultados significativamente diversos judicialmente? Um evento desses gera perplexidade e descrédito institucional.

Nesse campo, é também importante sinalizar aos agentes econômicos, principalmente aos estrangeiros, que os juízes e as demais autoridades aplicam as normas de forma previsível e imparcial, independentemente de eventuais relaçóes de amizade ou compadrio, mesmo quando houver confronto com pessoas ou empresas ligadas ao governo ou certos partidos políticos. A jurisprudência "cordial", além de antirrepublicana, é economicamente nociva. Todavia, é lamentável perceber que ainda nos dias de hoje:

determinados litigantes não têm qualquer preocupação com a previsibilidade. Preferem acreditar nas relaçóes de simpatia, estima e influências pessoais, reproduzindo a 'mentalidade cordial' que marcou o sujeito que, provindo de família patriarcal, passou a ocupar o espaço público sem abandonar os seus hábitos (MARINONI, 2016, p. 96).

Por fim, as instituiçóes devem estimular que os mercados funcionem de forma predominantemente livre, devendo eventuais intervençóes serem pontuais e terem por objetivo primordial neutralizar as chamadas "falhas do mercado" que, segundo Nusdeo

7 O sistema jurídico brasileiro, desde a Emenda Constitucional 45, de 30 de dezembro de 2004, que criou a Súmula Vinculante e a Repercussão Geral, vem inserindo preceitos com objetivo de induzir a uniformização da jurisprudência em todas as instâncias judiciais. A tendência foi incorporada pelo atual Código de Processo Civil de 2015 que, por meio de vários dispositivos, com destaque para o art. 927, procurou vincular o juiz às interpretaçóes superiores já postas. 
(2005, p. 143 e seg.), são: 1) rigidez de fatores ${ }^{8} ; 2$ ) assimetria de informaçóes relevantes ${ }^{9} ; 3$ ) concentração econômica ${ }^{10}$; 4) externalidades ${ }^{11}$; 5) utilização de bens coletivos ${ }^{12}$. Segundo o Nobel de Economia de 1998, Amartya Sen, "existem muitas evidências empíricas de que o sistema de mercado pode impulsionar o crescimento econômico rápido e a expansão dos padrôes de vida" (SEN, 2008, p. 41). Por tais motivos, na assertiva de Rodrigues (2007, p. 33), "o primeiro teorema da Economia do bem-estar, afirma precisamente que, respeitadas determinadas condiçóes, o resultado do funcionamento do mercado é eficiente".

De fato, vem se constatando existir uma relaçáo entre liberdade econômica (facilidade para abrir, operar e fechar negócios em geral) e o aumento da renda per capita. Nesse ponto específico, por exemplo, segundo estudo engendrado por Bender Filho et. al. (2007, p. 22): "Na área $5^{13}$, um aumento percentual na liberdade econômica gera um

8 Por exemplo, mercados que negociem bens cuja confecção encontre acentuada dificuldade para reagir aos estímulos (tanto para majoração, quanto para refreamento da produção), carecem da inserção de mecanismos capazes de minimizarem essa letargia, tais como uma CIDE (Contribuiçâo de Intervenção no Domínio Econômico), nos moldes autorizados pelo art. 149 da Constituição de 1988, a ser exigida periodicamente dos agentes envolvidos, com o intuito de, posteriormente, em casos de necessidade, financiar açóes que visem neutralizar os desequilíbrios que naturalmente surgem ao longo do tempo.

9 Em todos os produtos padronizados vendidos ao grande público ( $v$.g. remédios, alimentos, roupas, cigarros, eletrodomésticos, produtos para faxina, etc.) é natural que os fabricantes conheçam muito melhor as efetivas propriedades, qualidades e defeitos de tais produtos do que os compradores. Na assertiva de Farina (1997, p. 117): "Se compradores e vendedores não dispuserem de informaçóes necessárias para tomar suas decisões corretamente, o modelo de concorrência perfeita não funciona como previsto. Entretanto, a maioria dos consumidores náo têm consciência dos efeitos associados ao consumo de certos produtos". Portanto, face à notória desigualdade de informaçốes nas relaçôes de consumo, é que leis como o Código de Defesa do Consumidor trazem preceitos destinados a coibir - ou ao menos minimizar - a propaganda enganosa, bem como para obrigar o fabricante a indicar nas embalagens extensos dados acerca do produto posto à venda, tais como: prazo de validade, perigos potenciais, número de calorias, ingredientes, composição, maneiras de conservar, instruções de operação, etc.

10 Trata-se dos monopólios e oligopólios, eventos que podem influir no equilíbrio do mercado. Conforme Nusdeo (2005, p. 149), o bom funcionamento do mercado requer "um número razoavelmente elevado de compradores e vendedores em interação recíproca, e nenhum deles excessivamente grande ou importante". Segundo Rodrigues (2007, p. 162) "em concorrência perfeita as empresas conseguem apenas um lucro normal. Esta não é, portanto, uma alternativa interessante para o monopolista. É preferível vender uma quantidade menor por um preço mais elevado". Na lição de Posner (2007, p. 435), um efeito decorrente da concentração é "fazer com que alguns consumidores satisfaçam suas demandas por substituição a bens cuja produção seja mais custosa para a sociedade [...] O custo adicional é um desperdício para a sociedade" (tradução livre).

11 As externalidades, segundo Coelho (2007, p. 196), sáo "a tendência dos agentes econômicos de excluírem a própria responsabilidade por todos os custos necessários à sua produção e de, por outro lado, procurar apropriarse das vantagens, por circunstâncias provocadas por terceiros". Um exemplo clássico é a poluiçâo gerada pelas indústrias, derivando daí a necessidade de a legislação regular o tema, seja obrigando a instalaçăo de filtros, etc., seja sancionando os que descumprirem os preceitos ambientais.

$12 \mathrm{O}$ bem coletivo possui duas características marcantes, conforme Borati (2006, p. 73-74). Tais bens são "não excludentes", isso é, não é possível impedir alguém de desfrutá-lo, e também são "não rivais", pois o seu consumo pode ocorrer simultaneamente por mais de uma pessoa. Exemplo clássico é a defesa nacional, comodidade promovida pelo Estado que beneficia a todos residentes ao mesmo tempo. Noutro giro, a extinção de uma praga que afete determinada lavoura se caracteriza da mesma maneira, uma vez que os benefícios dessa empreitada se estendem a todos os agricultores daquele cultivo específico. Daí a necessidade, por exemplo, de a lei garantir uma patente a quem inventa pesticidas, adubos, remédios, etc. Ante a possibilidade de um comportamento "carona livre", é normal não haver grande incentivo para os particulares investirem preciosos recursos em pesquisas e outras tarefas afins com esse tipo de desiderato. Fato é que, segundo Nusdeo (2005, p. 164), "Uma economia fundada apenas no mercado tenderá a discriminar fortemente os bens coletivos e a exagerar a produção de bens exclusivos". Portanto, nesse campo, a regulação legislativa se faz necessária.

13 No caso, a referida área 5 corresponde a regulação do crédito, trabalho e negócios, com as seguintes subdivisões: 
aumento na renda per capita de $21 \%$ para os países desenvolvidos e de $14 \%$ para os em desenvolvimento". Em linha semelhante, são os trabalhos de ALBERTONI (2015) e FENNER (2016).

Com efeito, analisando-se o Índice de Liberdade Econômica 2018 (Freedom Index), publicado anualmente pela The Heritage Foundation (INDEX, 2018), contata-se que as primeiras posiçóes (maior liberdade) são justamente ocupadas por países cuja renda per capita é notoriamente elevada. São os casos de Hong Kong ( $1^{a}$ posição), Cingapura ( $2^{a}$ posição), Nova Zelândia (3a posição), Suíça (4 $4^{\mathrm{a}}$ posição) e Austrália (5 $5^{\mathrm{a}}$ posição). As cinco últimas posiçóes, quer dizer, aquelas relativas a países fechados e de economias altamente controladas pelos respectivos governos, são ocupadas por: República do Congo (176 a posição), Eritréia (177a posição), Cuba (178 a posição), Venezuela (179a posição) e Coreia do Norte (180 a posição). O Brasil ocupa a $153^{a}$ posição.

A tabela abaixo compara e faz uma relação entre a liberdade econômica e a renda per capita de cada país acima mencionado:

\begin{tabular}{|c|c|c|}
\hline $\begin{array}{c}\text { Posiçáo no Freedom } \\
\text { Index }\end{array}$ & País & ${\text { Renda per capita } \text { anual (em US\$ })^{14}}^{\mathbf{a}}$ \\
\hline $1^{\mathrm{a}}$ & Hong Kong & $61.500,00$ \\
\hline $2^{\mathrm{a}}$ & Cingapura & $34.100,00$ \\
\hline $3^{\mathrm{a}}$ & Nova Zelândia & $62.000,00$ \\
\hline $4^{\mathrm{a}}$ & Suíça & $40.400,00$ \\
\hline $5^{\mathrm{a}}$ & Austrália & $15.600,00$ \\
\hline $153^{\mathrm{a}}$ & Brasil & $6.800,00$ \\
\hline $176^{\mathrm{a}}$ & República do Congo & $1.600,00$ \\
\hline $177^{\mathrm{a}}$ & Eritréia & $12.300,00$ \\
\hline $178^{\mathrm{a}}$ & Cuba & $12.500,00$ \\
\hline $179^{\mathrm{a}}$ & Venezuela & $1.700,00$ \\
\hline $180^{\mathrm{a}}$ & Coreia do Norte & \\
\hline
\end{tabular}

Comparando-se a situação brasileira com outros países da América Latina, tem-se o seguinte quadro:

\begin{tabular}{|c|c|c|}
\hline $\begin{array}{c}\text { Posiçáo no Freedom } \\
\text { Index }\end{array}$ & País & Renda per capita anual (em US\$) $^{15}$ \\
\hline $18^{\mathrm{a}}$ & Chile & $24.600,00$ \\
\hline $40^{\mathrm{a}}$ & Uruguai & $22.400,00$ \\
\hline $45^{\mathrm{a}}$ & Peru & $13.500,00$ \\
\hline $49^{\mathrm{a}}$ & Colômbia & $14.400,00$ \\
\hline $5^{\mathrm{a}}$ & Paraguai & $12.800,00$ \\
\hline
\end{tabular}

A) Regulaçôes no mercado de crédito; B) Regulaçôes do mercado de trabalho; C) Regulaçôes de negócios. 14 Fonte: UNITED STATES OF AMERICA. Central Intelligence Agency. The world fact book.

15 Fonte: idem nota anterior. 


\begin{tabular}{|c|c|c|}
\hline $148^{\mathrm{a}}$ & Argentina & $20.900,00$ \\
\hline $165^{\mathrm{a}}$ & Equador & $11.500,00$ \\
\hline $166^{\mathrm{a}}$ & Suriname & $14.900,00$ \\
\hline $173^{\mathrm{a}}$ & Bolívia & $7.600,00$ \\
\hline
\end{tabular}

Além do que acima já foi referido, para que haja crescimento econômico sustentável é necessário que as instituiçóes de um país sejam moldadas de modo a: 1) estimularem a educação, a qualificação da mão de obra (capital humano) e a acumulação de conhecimento (tecnologia); 2) induzirem as pessoas a terem baixa tolerância com a corrupção de agentes públicos ou privados e 3) permitirem que o jogo social se opere dentro de um ambiente democrático, com ampla liberdade política, de manifestação do pensamento e de imprensa, sem qualquer espécie de censura oficial.

A educação e a qualificação da mão de obra se ligam à produtividade de uma sociedade. É a produtividade que indica a relação entre o input (matéria prima, ingredientes, insumos) e o output (bens e serviços produzidos). Quanto mais qualificada for uma população, quanto mais instruídas forem as pessoas como um todo, melhor para a produtividade, sendo certo que essa sociedade conseguirá produzir mais (output) com menos (input).

Tanto é assim que os países que desde cedo se preocuparam em alfabetizar a uma parcela relevante da respectiva população se saíram significativamente melhores do que aqueles que legaram essa preocupação a um segundo plano, como foi, infelizmente, o caso brasileiro.

Assim, por exemplo, nos Estados Unidos da América, "Em 1850, 97\% da população era alfabetizada. Mais de vinte anos depois (1872) essa proporção era de apenas 15\% no Brasil" (NÓBREGA, 2005, p. 87). O autor ainda menciona que no Japão a educação feminina já havia se tornado uma preocupação há mil anos, bem como chama a atenção para o fato das crianças da Coréia do Sul permanecerem até onze horas diárias na escola. Aliás, nos "anos 80, o Brasil e a Coreia do Sul tinham índices de produtividade semelhantes. Hoje, o que um coreano produz em um dia, um brasileiro produz em três" (COSTAS, 2014), o que muito provavelmente é explicado pelo nível de atenção com a educação (incluindo a qualificação da mão de obra) que cada país apresentou nas últimas décadas.

Ademais, é certo que a qualificação profissional não é algo que interesse apenas à sociedade ou ao país. Nessas situações, as pessoas em geral têm aumentadas as chances de conseguirem trabalho e de obterem vantagens salariais e, com isso, aumentarem o respectivo bem-estar e qualidade de vida. Nesse tópico, conforme Tamamar (2010, sem paginação): 
A chance de um trabalhador com formação de tecnólogo, ensino médio técnico ou com qualificação profissional (especialização básica de curta duração) conseguir um emprego é $48,2 \%$ maior do que a de uma pessoa sem tais cursos. Quem investe em educação profissional ainda tem salário $12,94 \%$ mais alto, além de uma possibilidade $38 \%$ maior de conseguir uma vaga formal. Os dados fazem parte do estudo feito pelo Centro de Estudos e Políticas Sociais da Fundação Getúlio Vargas (FGV) e pelo Instituto Votorantim.

Contudo, infelizmente, a educação no Brasil claudica há décadas. Segundo Giambiagi e Pinheiro (2012, p. 123), em que pese "o vultoso aumento de recursos nos últimos anos, os resultados brasileiros continuam muito aquém dos padróes mínimos considerados aceitáveis". Com base em vários estudos, pesquisas e comparaçóes com outros países, os autores acima são enfáticos: "não há, no Brasil, uma região sequer que consiga aumentar o percentual de alunos com desempenho adequado ao longo do ciclo escolar. Os alunos brasileiros simplesmente não estão aprendendo o suficiente" (ob. cit., p. 126).

Prosseguindo, outro fator de grande relevo que impulsiona o desenvolvimento é a capacidade de uma sociedade criar e acumular conhecimento, notadamente por meio de bens imateriais legalmente protegidos como as marcas, os desenhos, as patentes e os segredos industriais. Aliás, uma das características da Sociedade da Informação é o fato de os bens imateriais ligados ao conhecimento valerem, em termos econômicos, mais do que o conjunto de bens materiais (geralmente bens de consumo) produzidos com esteio nos primeiros. Com efeito, "os ativos do conhecimento, isto é, o capital intelectual, passaram a ser mais importantes para as empresas que os ativos financeiros e físicos" (LISBOA, 2007, p. 121).

Tanto é assim que, segundo Forgioni (2015, p. 303), “a propriedade intelectual é o maior produto de exportação dos Estados Unidos" ${ }^{16}$. Nesse contexto, por exemplo, notase que não obstante diversos produtos eletrônicos como Iphones, Ipads, Tablets, etc. serem usualmente montados em países como a China ou o Vietnam, o complexo tecnológico neles embutido é quase todo de propriedade de empresas norte-americanas ou europeias, que, evidentemente, cobram royalties nada módicos das companhias ao redor do mundo que queiram importar, montar ou mesmo comercializar tais aparelhos.

As demais características das instituiçóes que contribuem para alavancar o desenvolvimento serão vistas nos próximos itens. São elas: induçáo das pessoas a terem baixa tolerância face à corrupção e a presença de um ambiente democrático, com ampla liberdade de crítica.

16 Essa tendência, aliás, já era percebida nas últimas décadas do século XX. Em 1980, por exemplo, Toffler (1980, p. 162) asseverou que "a informação tornou-se talvez o negócio mais importante e o que mais cresce no mundo". 


\section{Os movimentos sociais de junho de 2013 no Brasil}

No mês de junho de 2013, algo inusitado ocorreu no Brasil, em termos de exercício da cidadania, a partir de protestos e reinvindicaçóes populares públicas. Como sabido, naquela ocasião, milhóes de pessoas saíram às ruas de diversas. Naquele momento estavam em cena duas crises sérias no país: uma de cunho econômico e a outra de índole política.

Com efeito, em junho de 2013 eram sentidos os efeitos da crise mundial dos chamados títulos sub prime, deflagrada em 2007 nos Estados Unidos e que afetou negativamente o mundo todo, inclusive o Brasil. O forte crescimento econômico experimentado nos anos anteriores havia ficado para trás e as perspectivas para o futuro pioravam constantemente.

Em termos políticos, no início de 2013 encerrou-se no Supremo Tribunal Federal o julgamento do chamado "caso mensalão" (Ação Penal no 470), com a condenação por corrupção e lavagem de dinheiro de pessoas com fortes ligaçóes e proximidade com o governo federal. Nunca antes um julgamento havia experimentado tamanha cobertura por parte da imprensa. As posiçôes dos Ministros do STF, muitas vezes antagônicas e acaloradas, foram retratadas com afinco pelos mais importantes meios de comunicação do país.

Nesse contexto, mesmo sem perceber claramente, o fato é que em junho de 2013 muitas pessoas estavam desgostosas com os rumos que a nação tomara. Contudo, aparentemente, havia certa passividade ou resignação reinante no ambiente, ou seja, até então esse desgosto geral não havia aflorado de modo claro e incontestável. Todavia, quando o entáo Prefeito de Sáo Paulo anunciou que as passagens de ônibus aumentariam em $\mathrm{R}$ \$ 0,20, passando de $\mathrm{R} \$ 3,00$ para $\mathrm{R} \$ 3,20$, o silêncio se quebrou de forma repentina.

Como que por milagre o clima mudou radicalmente e de forma muito rápida. Quase que imediatamente eclodiram diversas manifestaçóes nas ruas, inicialmente na Capital paulista, mas logo se espalharam Brasil afora. A suposta causa inicial (protesto contra o aumento das passagens de ônibus) foi logo substituída por uma pauta bem mais amplificada. Com efeito, o que se reivindicava era uma reforma política substancial, com intensidade suficiente para extirpar a corrupção e as atitudes nada republicanas da maioria da classe política brasileira.

Curiosamente, a composição dos manifestantes era bastante heterogênea, com a presença de estudantes, aposentados, empresários, empregados, desempregados, funcionários públicos, donas de casa, etc. É fato que muitas dessas pessoas nunca havia ido às ruas para manifestar indignação contra a política, provavelmente por identificar esse tipo de movimento como algo orquestrado por partidos políticos ou sindicatos. Conforme o relato jornalístico de Melo (2014, sem paginação): 
$\mathrm{Na}$ noite de 20 de junho de 2013, as ruas de dezenas de cidades brasileiras foram tomadas por 1,5 milhão de manifestantes. Era o ápice de uma inédita onda de protestos que balançaram o país, assustaram os governantes e chamaram a atenção do mundo. Os motivos para a insatisfação eram numerosos e variados, estilhaçando reivindicaçóes para todos os cantos, mas identificava-se um sentimento geral: a indignação com a classe política. Os brasileiros estavam nas ruas porque sentiam-se abandonados por seus representantes. Uma pesquisa feita pelo Ibope mostrava que $83 \%$ náo se consideravam representados por qualquer político. Uma proporção ainda maior, $89 \%$, achava que nenhum partido agia em nome de seus interesses.

Igualmente, nota-se que em junho de 2013 não houve prévia convocação por parte de sindicatos, associações, entidades de classe ou mesmo partidos políticos de oposição. Toda a movimentação surgiu meio que espontaneamente no seio de diversas redes sociais que utilizam a internet como base. Inegável, pois, o papel fundamental dessas redes para a eclosão dos protestos, outro reflexo da era da Sociedade da Informação, qual seja, a circulação de ideias, informações e conhecimento em termos globais, a velocidades nunca vistas e a custos cada vez menores.

Náo houve partido político que tenha restado imune às críticas. Literalmente todos foram fortemente atacados pelas redes sociais e pela própria imprensa. Evidentemente, por uma questão de proeminência na vida nacional, o partido do governo sofreu a maior parte dos ataques. Posteriormente, outras manifestaçóes assemelhadas vieram à tona, citando-se como exemplo aquelas do início de 2016 que pleiteavam o impeachment da presidente Dilma Rousseff, o que, de fato, acabou ocorrendo ainda no mesmo ano. Nesse e em outros episódios, o papel das redes sociais para a mobilização das pessoas foi crucial, ao mesmo tempo em que partidos políticos, sindicatos e associaçóes "oficiais" tiveram papel coadjuvante.

Mas "junho de 2013" foi certamente o ponto inicial desse tipo de manifestação social predominantemente apartidária que, em nossa opinião, marcou uma nova forma de exercer a cidadania, uma cidadania quase direta, isso é, descolada da classe política ou dos mecanismos tradicionais de representação. Nesse peculiar contexto, os movimentos de junho de 2013 igualmente podem ser vistos como um inegável sinal de evoluçáo institucional que claramente demonstrou a redução da tolerância das pessoas para com a corrupção da classe política.

Naquela ocasiáo, as pessoas igualmente descobriram que ir às ruas era apenas uma das maneiras de deixar clara a insatisfação, na medida em que as redes eletrônicas poderiam ser largamente utilizadas (e foram) com o mesmo propósito. Portanto, o ambiente virtual definitivamente entrou em cena como instrumento de manifestação do pensamento e exercício de crítica, e assim vem permanecendo. 


\section{Renovaçáo do exercício da cidadania}

Conforme acima dito, o desenvolvimento de um país é mais bem engendrado se a dinâmica social se operar sob um ambiente democrático em que impere a liberdade de manifestaçáo de pensamento e crítica. Aliás, a democracia, por si só, pode ser uma grande aliada do crescimento econômico. Com efeito:

O funcionamento da democracia e dos direitos políticos pode até mesmo ajudar a impedir a ocorrência de fomes coletivas e outros desastres econômicos. Os governos autoritários, que raramente sofrem os efeitos de fomes coletivas (ou de outras calamidades econômicas como essa), tendem a náo ter estímulos para tomar providências preventivas oportunas. Os governos democráticos, em contraste, precisam vencer eleiçôes e enfrentar a crítica pública, dois fortes incentivos para que tomem medidas preventivas contra aqueles males (SEN, 2008, p. 30).

A conjuntura decorrente de “junho de 2013" implantou um novo patamar na democracia brasileira, tendo contribuído para aprimorar os modos de compreender e, sobretudo, exercer a cidadania, náo mais vista em termos meramente formais como o direito de votar e ser votado, mas como algo bem amplo e ligado a um sentimento genuíno dos indivíduos de pertença a certo grupo e de corresponsabilidade pelos destinos desse grupo.

Na mesma linha, "junho de 2013" também marcou uma ampliação dos limites do direito de manifestação do pensamento e opinião dos cidadãos, o que, guardadas as devidas proporçóes, insere ares de "democracia direta" no Brasil. Afinal, o direito de opinião com potencial efetivo para influenciar os rumos do país não pode ficar restrito aos Parlamentos e na garantia do direito ao voto por ocasiáo das eleiçóes. Nesse tópico, coloca Bobbio (1988, p. 157) que:

Hoje, quem deseja um indicador do desempenho democrático de um país deve considerar não mais o número de pessoas que têm direito de votar, mas o número de instâncias diversas daquelas tradicionalmente políticas nas quais se exerce o direito de voto. Em outros termos, quem deseja dar um juízo sobre o desenvolvimento da democracia num dado país deve pôr-se não mais a pergunta "Quem vota?", mas "Onde se vota?"

Em síntese, Aieta (2006, p. 198) argumenta que o grau de democracia das sociedades ocidentais não depende apenas das eleiçôes livres, como também da possibilidade de debate político real. Em suas palavras: "o desejo de uma sociedade mais democrática implica, obrigatoriamente, o necessário afastamento das práticas políticas do despotismo eletivo que pretende, muitas vezes, se justificar pelo voto popular". No mesmo caminho, Barroso (2007, p. 03) assevera que na "configuração contemporânea do Estado e da sociedade, a idéia de democracia já não se reduz à prerrogativa popular de eleger representantes, nem tampouco às manifestaçóes das instâncias formais do processo majoritário”. 
Ora, esse tipo de cidadania amplificada não seria possível fora dos pilares da Sociedade da Informação, onde, conforme já dito, ideias, informaçóes e conhecimento circulam de forma cada vez mais rápida e atingem um público maior. Não seria possível também caso no Brasil não se vivesse sob um ambiente democrático inspirado pela liberdade de manifestação do pensamento e pela ampla liberdade da imprensa.

Acreditamos que essa nova concepçáo do exercício da cidadania seja capaz de exercer pressáo sobre os poderes instituídos e seus componentes, eis que insere no contexto a possibilidade de constante exame e crítica popular, inclusive através das redes sociais cujo conteúdo se pulveriza por milhóes de pessoas. Isso demonstra que todos aqueles que direta ou indiretamente estiverem envolvidos com a "coisa pública" (governantes, parlamentares, autoridades, servidores, etc.) estão muito mais vulneráveis ao escrutínio social do que há quinze ou vinte anos, o que se tem mostrado muito promissor em termos de evolução institucional. Aliás, a propagação de ideais por meio eletrônicos já colocou em xeque a estabilidade de vários governos e literalmente já apeou do trono alguns caudilhos (v.g., a chamada Primavera Árabe).

E quais seriam os reflexos deixados por "junho de 2013" na sociedade brasileira? Haveria saldo positivo a considerar atualmente? Entendemos que a resposta é afirmativa, nos seguintes termos:

Para a doutora em políticas sociais pela Universidade de Brasília (UnB) Maria Lúcia Lopes da Silva, junho de 2013 foi "um mês que não terminou". A professora do curso de serviço social afirma que os atos daquele momento dialogam diretamente com a conjuntura política atual. "As Jornadas de Junho foram uma referência, do ponto de vista da retomada dos movimentos de massa com um nível de organização maior”, explica. "Naquela época, a mobilização via redes sociais foi grande. Resultou na definição maior dos projetos políticos ideológicos, e na relaçấo dos movimentos de massa, do ponto de vista institucional" (MARQUES, 2018, sem paginação).

Em suma, duas liçóes podem ser tiradas dos movimentos de “junho de 2013". A primeira é que as redes sociais eletrônicas são extremamente eficazes em mobilizar os cidadãos para fins políticos, tendo sido colocados em segundo plano, ao menos naquela ocasião, os tradicionais atores dessa arena, como partidos políticos, sindicatos e associaçóes de classe.

A segunda lição, talvez a mais importante, é que ficou bastante claro que a sociedade brasileira, de um modo abrangente, está notavelmente menos tolerante com a corrupção de governantes, parlamentares e autoridades públicas, o que interpretamos como importante avanço institucional que tende a contribuir para o desenvolvimento do país. 


\section{Conclusóes}

As instituiçóes são compostas não apenas pelas normas jurídicas, mas também pelos modos e extensão de como são aplicadas. Compóem igualmente as instituições os valores, as convençôes e as crenças sociais consolidadas ao longo do tempo. Atualmente, as instituiçôes são vistas como os principais fatores que contribuem (ou não) para o desenvolvimento de um país, isso é, a circunstância de a maioria da população viver sob condiçóes materiais dignas.

O desenvolvimento requer e pressupóe o crescimento da economia que, para ocorrer de forma sustentável, necessita do seguinte: 1) respeito à propriedade e aos contratos; 2) segurança jurídica e previsibilidade do comportamento judicial; 3) aplicação impessoal e isonômica da lei, sem privilégios ou distinções infundadas e 4) sistema de mercado predominantemente livre, devendo as intervençôes estatais serem direcionadas sobretudo para neutralizar eventos como rigidez de fatores, assimetria de informaçóes, abuso do poder econômico e externalidades.

Todavia, levando em conta que crescimento e renda per capita elevada, por si só, não gera desenvolvimento, é indispensável que as instituições igualmente: 1) estimulem a educação pública, a qualificação da mão de obra (capital humano) e a acumulação de conhecimento (tecnologia); 2) induzam as pessoas a terem baixa tolerância com a corrupção de agentes públicos ou privados e 3) permitam que o jogo social se opere dentro de um ambiente democrático, com ampla liberdade política, de manifestação do pensamento e de imprensa, sem qualquer espécie de censura oficial.

No que se refere aos dois últimos requisitos, merecem destaque as manifestaçóes e protestos públicos ocorridos no Brasil em junho de 2013. Tais movimentos, da forma como ocorreram, somente foram possíveis em face atual Sociedade da Informação, período marcado pela cada vez mais rápida circulação de ideias, informações e conhecimento, bem como pelo fato de o conjunto dos bens imateriais produzidos superar, em termos econômicos, o valor dos bens materiais. Da mesma forma, caso não se vivesse no Brasil sob um ambiente democrático consolidado, onde o direito de manifestação do pensamento crítico e a liberdade de imprensa efetivamente imperassem, dificilmente as manifestaçóes teriam sido tão intensas. Talvez sequer fossem deflagradas.

Fato é que, em junto de 2013 essa conjuntura (Sociedade da Informação mais ambiente democrático) abriu espaço para a valorização do exercício da cidadania, não mais aquele exercido precipuamente no momento de depositar o voto em urna, mas num sentido inovador e amplificado para agregar às pessoas o poder de fiscalizar e, sobretudo, influenciar o comportamento de governantes, parlamentares e autoridades, tendo como mote a exigência de posturas sempre impessoais, transparentes e em harmonia com os princípios republicanos. 
Foi o que, em síntese, ocorreu em junho de 2013, sendo certo que as diversas manifestaçôes públicas, com milhôes de participantes em diversas cidades brasileiras, tinham como principal pano de fundo o protesto contra a corrupção de parcela significativa da classe política nacional, o que, por conseguinte, demonstra nitidamente uma diminuição da tolerância das pessoas para com a corrupção se comparado a períodos mais distantes.

E, levando em conta que todas as mobilizaçóes tiveram origem precipuamente através das redes sociais operadas na internet, sem participação ou convocação prévia por partidos políticos, sindicatos ou associaçóes congêneres, consideramos que "junho de 2013" representou um marco inaugural de uma nova maneira, quiçá mais direta e incisiva, de se exercer a cidadania em aprimoramento da democracia.

Desse modo, consideramos que duas liçôes podem ser tiradas dos movimentos de "junho de 2013". A primeira é a grande eficácia das redes sociais eletrônicas em mobilizar os cidadãos para fins políticos, o que, de certa forma, deixou em segundo plano os tradicionais protagonistas das grandes mobilizaçóes, tais como partidos políticos, sindicatos e associaçóes de classe. A segunda lição foi ter restado claro que a sociedade brasileira, como um todo, está notavelmente menos tolerante com a corrupção, o que certamente representa um inegável avanço institucional a se integrar no caminho do desenvolvimento.

\section{Referências}

ACEMOGLU, Daron; ROBINSON, James. Por que as naçôes fracassam: as origens do poder, da prosperidade e da pobreza. Trad. Cristiana Serra. São Paulo: Companhia das Letras, 2012.

AIETA, Vânia Siciliano. Democracia: estudos em homenagem ao prof. Siqueira Castro. Rio de Janeiro: 2006.

ALBERTONI, Diego Augusto Cadore. Liberdade econômica: o caminho para o crescimento econômico. Monografia (habilitação para a obtenção do título de Bacharel em Ciências Econômicas). Universidade Federal de Santa Maria, 2015. Disponível em: http://coral.ufsm.br/economia/wp-content/uploads/2016/03/LIBERDADEECON\% C3\%94MICA-O-Caminho-para-o-Crescimento-Econ\%C3\%B4mico-Diogo-AugustoCadore-Albertoni-.pdf. Acesso em: 03 jun. 2018.

APPY, Bernard; SANTI, Eurico Marcos Diniz de; COELHO, Isaias; MACHADO, Nelson. Reforma de qualidade do sistema tributário. Migalhas, 29/04/2016. Disponível em:http://www.migalhas.com.br/dePeso/16,MI238426,71043-Reforma+da+qualidade +do+sistema+ tributario. Acesso em: 30 mai. 2018. 
BARRAL, Welber. Direito e desenvolvimento: um modelo de análise. In: BARRAL, Welber (org.). Direito e desenvolvimento. São Paulo: Singular, 2005, p. 31-60.

BARROS, Ricardo Paes de; MENDONÇA, Rosane. O impacto do crescimento econômico e de reduçóes no grau de desigualdade sobre a pobreza. Instituto de Pesquisa Econômica Aplicada - IPEA - texto para discussão n. 528, nov. 1997. Disponível em: http://repositorio.ipea.gov.br/ bitstream/11058/2379/1/td_0528.pdf.

BARROSO, Luís Roberto. Introdução: a reconstrução democrática do direito público no Brasil. In: BARROSO, Luís Roberto (Org.). A reconstrução democrática do direito público no Brasil. Rio de Janeiro: Renovar, 2007, p. 01-39.

BENDER FILHO, Reisoli; SONAGLIO, Cláudia Maria; ZAMBERLAN, Carlos Otávio. Instituições, liberdade econômica e crescimento: uma análise de países desenvolvidos e em desenvolvimento. Pesquisa \& Debate, São Paulo, vol. 24, n. 2 (44), p. 243-266, jul./dez. 2013. Disponível em: https://revistas.pucsp.br/index.php/rpe/ article /view/17712/13201. Acesso em: 03 jun. 2018.

BOBBIO, Norberto. Estado, governo e sociedade: para uma teoria geral da política. Trad. Marco Aurélio Nogueira. 2. ed., São Paulo: Paz e Terra, 1988.

BORATI, Vanessa. Economia para o direito. Barueri: Manole, 2006.

BRASIL. Código de Processo Civil de 2015. Lei n. 13.105, de 16 de março de 2015. Disponível em: http://www. planalto.gov.br/ccivil_03/_ato2015-2018/2015/lei/1131 05.htm. Acesso em: 16 fev. 2019.

BRASIL. Constituição da República Federativa do Brasil, de 05 de outubro de 1988. Brasília: Senado Federal, 1988. Disponível em: http://www.planalto.gov.br/ccivil_03/ Constituicao/Consti tuicao.htm. Acesso em: 02 fev. 2019.

COELHO, André Felipe Canuto. A necessária interação entre o direito e a economia diante da regulação do estado na ordem econômica. Revista de Direito Administrativo \& Constitucional, Curitiba, n. 27, p. 185-206, n. 27, jan./mar. 2007.

COOTER, Robert; ULEN, Thomas. Direito \& economia. Trad. Luis Marcos Sander; Francisco de Araújo da Costa. Porto Alegre: Bookman, 2010.

COSTA, Regina Helena. Repercussão geral em matéria tributária: primeiras reflexóes. In: PAULSEN, Leandro (coord.). Repercussão geral no recurso extraordinário. Porto Alegre: Livraria do Advogado, 2011, p. 109-117.

COSTAS, Ruth. Quatro estratégias para aumentar produtividade no Brasil. BBC Brasil, 02/06/2014. Disponível em: http://www.bbc.com/portuguese/ noticias/2014/06/140425_produtividade_estrate gias_ru. Acesso em: 03 mai. 2019. 
FARINA, Elisabeth. Competitividade: mercado, estado e organizações. São Paulo: Singular, 1997.

FENNER, Mayara. A relação entre liberdade econômica e nivel de bem-estar. Monografia (habilitação para a obtenção do título de Bacharel em Ciências Econômicas). Universidade Federal de Santa Maria, 2015. Disponível em: http://coral.ufsm.br/ economia/wp-content/uploads/2016/03/A-RELA\%C3\%87\%C3\% 83O-ENTRELIBERDADE-ECON\%C3\%94MICA-E-N\%C3\%8DVE-DE-BEM-EST AR-MayaraFenner.pdf. Acesso em: 04 abr. 2019.

FORGIONI, Paula Andrea. Análise econômica do direito: paranóia ou mistificação? Revista do Tribunal Regional Federal da $3^{a}$ Região, São Paulo, n. 77, p. 35-61, mai./jun. 2006.

FORGIONI, Paula Andrea. Fundamentos do antitruste. 8. ed., São Paulo: Revista dos Tribunais, 2015.

GALA, Paulo. A teoria institucional de Douglass North. Revista de Economia Politica, São Paulo, vol. 23, n. 2, p. 89-105, abr./jun. 2003.

HARDIN, Garret. The tragedy of the commons. Science - New Series, Washington, vol. 162, n. 3.859, p. 1.243-1.248, dez. 1968. Disponível em: https://pages.mtu. edu/ asmayer/rural_sustain/governance/Hardin\%201968.pdf. Acesso em: 31 mar. 2019.

INDEX of economical freedom - 2019. The Heritage Foundation. Disponível em: https://www.heritage.org/index/. Acesso em: 11 mai. 2019.

LIMA, Ediberto Carlos Pontes. Reforma tributária no Brasil: entre o ideal e o possível. Instituto de Pesquisa Econômica Aplicada - IPEA, texto para discussão n. 666, ago. 1999. Disponível em: <http://www.ipea.gov.br/agencia/images/stories/PDFs/TDs/td_ 0666. pdf>. Acesso em: 30 mai. 2018.

LISBOA, Roberto Senise. O consumidor na sociedade da informação. In: PAESANI, Liliana Minardi (Coord.). O direito na sociedade da informação. São Paulo: Atlas, 2007, p. 113-142.

MARINONI, Luiz Guilherme. A ética dos precedentes: justificativa do novo CPC. São Paulo: Revista dos Tribunais, 2016.

MARTINS, Marcelo Guerra. Contratos incompletos e sua interpretação na era da informação. Revista de Direito Empresarial, ano 13, n. 3, p. 97-113, set./dez. 2016.

MARQUES, Marília. Junho de 2013: relembre os atos em Brasília e veja o que mudou 5 anos depois. G1-DF, 13/06/2018. Disponível em: https:/g1.globo.com/df/distritofederal/ noticia/junho-de-2013-relembre-os-atos-em-brasilia-e-veja-o-que-mudou-5anos-depo is.ghtml. Acesso em: 14 jun. 2018. 
MELO, Itamar. O que sobrou dos protestos de junho de 2013. Disponível em: https:// gauchazh.clicrbs.com.br/politica/eleicoes-2014/noticia/2014/10/O-que-sobrou-dos-pro testos-de-junho-de-2013-4613638.html. Acesso em: 31 mai. 2018.

NÓBREGA, Maílson da. Brasil: o futuro chegou. São Paulo: Globo, 2005.

NORTH, Douglass C. Institutions, transaction costs, and the rise of merchant empires. The political economy of merchant empires. Cambridge: James D. Tracy, p. 22-40, 1991.

NORTH, Douglass C. Economic performance through time. The American Economic Review, vol. 84, n. 03, p. 359-368, jun. 1994.

NUSDEO, Fábio. Curso de economia: introdução ao direito econômico. 4. ed., São Paulo: Revista dos Tribunais, 2005.

PINHEIRO, Armando Castelar. PIB potencial e segurança jurídica no Brasil. In: SICSÚ, João; MIRANDA, Pedro (orgs.). Crescimento econômico: estratégias e instituições. Rio de Janeiro: IPEA, 2009, p. 25-53.

POSNER, Richard. El análisis económico del derecho. 2. ed. Trad. para o espanhol de Eduardo L. Suárez. México: Fondo de Cultura Económica, 2007.

RODRIGUES, Vasco. Análise económica do direito. Coimbra: Almeidina, 2007.

SACHS, Jeffrey. O fim da pobreza. Trad. Pedro Maia Soares. São Paulo: Companhia das Letras, 2005.

SEN, Amartya. Desenvolvimento como liberdade. 7. reimp. Trad. Laura Teixeira Motta. São Paulo: Cia. das Letras, 2008.

SERPA LOPES, Miguel Maria de. Curso de direito civil - fontes das obrigaçôes: contratos. 6. ed., Rio de Janeiro: Freitas Bastos, vol. 3, 1996.

SOUZA, Nali de Jesus de. Desenvolvimento econômico. 5. ed., São Paulo: Atlas, 2008.

SZTAJN, Raquel e VERÇOSA, Haroldo Malheiros Dulcrec. A incompletude do contrato de sociedade. Revista de Direito Mercantil Industrial Econômico e Financeiro. vol. 131, p. 7-20, jul./set. 2003.

TAMAMAR, Gisele. Salário de trabalhador com mais estudo aumenta 13\%. Estadão - Seu Bolso, 27/05/2010. Disponível em: http://www.estadao.com.br/blogs/jt-seubolso/2010/05/27/salario-de-trabalhador-com-mais-estudo-aumenta-13/. Acesso em: 30 abr. 2018.

TOFFLER, Alvin. A terceira onda. 18. ed., São Paulo: Record. 1980. 
UNITED STATES OF AMERICA. Central Intelligence Agency. The world fact book. Disponível em: https://www.cia.gov/library/publications/the-world-factbook/. Acesso em 10 mai. 2019.

ZYLBERSZTAJN, Décio; SZTAJN, Raquel. Análise econômica do direito e das organizaçôes. In: ZYLBERSZTAJN, Décio; SZTAJN, Raquel (orgs.). Direito \& economia. Rio de Janeiro: Campus, 2005, p. 01-15. 